\title{
PENERAPAN PROSEDUR OPERASIONAL FLOATING DOCK 6000 TLC
}

\author{
Bambang Sudjasta \\ Program Studi Teknik Perkapalan-FakultasTeknik, UPN "Veteran” Jakarta, Jakarta Selatan, Indonesia \\ Email : karebet_m@yahoo.co.id
}

\begin{abstract}
Floating dock is one of the places for the repair of ship. It is a building that float on the sea, and has the ability to raise the vessel with longitudinal or transverse slope sizeable. It is needed a stable balance during the docking operation. In the implementation of docking the vessel must pay attention to the security elements of material and personnel. Should be avoided for slope occurring and ensuring the security and safety of the ship docking process. The implementation should always follow established procedures. the implementation should always follow established procedures.
\end{abstract}

Keywords: stability, prosedur, TLC

\section{PENDAHULUAN}

\section{Latar Belakang}

Floating dock (dok apung) merupakan salah satu bentuk alat apung yang berguna sebagai tempat untuk membangun atau memperbaiki kapal. Disamping itu karena dok apung merupakan suatu bangunan yang terapung maka diperlukan keseimbangan yang stabil dan stabilitas yang baik dari dok apung itu sendiri, untuk dapat menjamin keamanan dan keselamatan dalam proses pengedokan kapal.

Ditinjau dari cara kerja floating dock adalah menenggelamkan dan mengapungkan diri sambil mengangkat kapal yang dinaikkan dok dengan arah vertikal maka, dari kedua kondisi tersebut dibutuhkan suatu sistim pengaturan dan pengontrolan untuk menjaga kestabilan terhadap kemiringan memanjang dan melintang yang cukup besar pada saat dok apung beroperasi. Untuk menjaga kemiringan memanjang dan melintang yang cukup besar pada saat dok apung beroperasi diperlukan suatu unit pengontrol yang dapat membantu di atas dok sehingga terhindar dari kejadiankejadian yang dapat merugikan dari pihak pemilik kapal atau dari pihak galangan itu sendiri.

Dalam melakukan perawatan bawah air tentunya kapal harus bebas dari air dengan menggunakan dock apung. Dengan alat ini kapal akan diangkat dari laut, proses ini biasa disebut dengan docking. Pada saat dock naik ke permukaan air dengan mengangkat kapal yang akan diperbaiki atau direparasi agar berjalan lancar sesuai rencana tentunya stabilitas dok apung harus terjaga dengan baik.

\section{Tujuan}

1. Mengetahui prosedur pengaturan dan pengontrolan terhadap pengisian atau pengeluaran air di dalam ponton-ponton untuk tetap stabil apabila terjadi kemiringan melintang ataupun kemiringan memanjang akibat pengaruh perpindahan fluida/air di dalam ponton-ponton pada saat dok menaikkan kapal

2. Untuk mengetahui secara prosedur pengoperasian floating dock agar pengoperasian tersebut berjalan dengan stabil.

3. Mengetahui suatu penerapan sistem stabilitas floating dock pada saat beroperasi yaitu pengatur untuk menjaga kestabilan terhadap kemiringan memanjang dan kemiringan melintang.

\section{TINJAUAN PUSTAKA \\ Floating Dock (Dok Apung)}

Adalah suatu bangunan konstruksi yang dipasang dari sebuah atau beberapa kompartemen yang kedap air pada sisi-sisinya dan terbuka pada kedua ujungnya. Dapat ditenggelamkan dengan mengisi kompartemen tersebut dengan air dan kapal akan memasukinya pada saat bangunan tersebut tenggelam. Dan akan ke permukaan air lagi (timbul) dengan jalan memompa air keluar dari kompartemen-kompartemen. Pada 
umumnya dock apung dibuat dengan konstruksi baja, yang berupa bangunan berbentuk pontoon, sehingga dapat dipindahkan dari satu tempat ke tempat lain dengan ditarik Tug Boat. Kedudukan dok apung terhadap permukaan air dapat berubah sesuai kebutuhan. Hal ini berarti adanya sistem pontoon yang merupakan ciri khusus dari setiap dock apung. Ukuran bervariasi dari kecil (ratusan ton) sampai yang besar (ribuan ton). Dibandingkan dengan dok gali / kolam, biaya pembuatan dok apung relatif lebih rendah, tetapi biaya operasi dan pemeliharaan lebih tinggi.

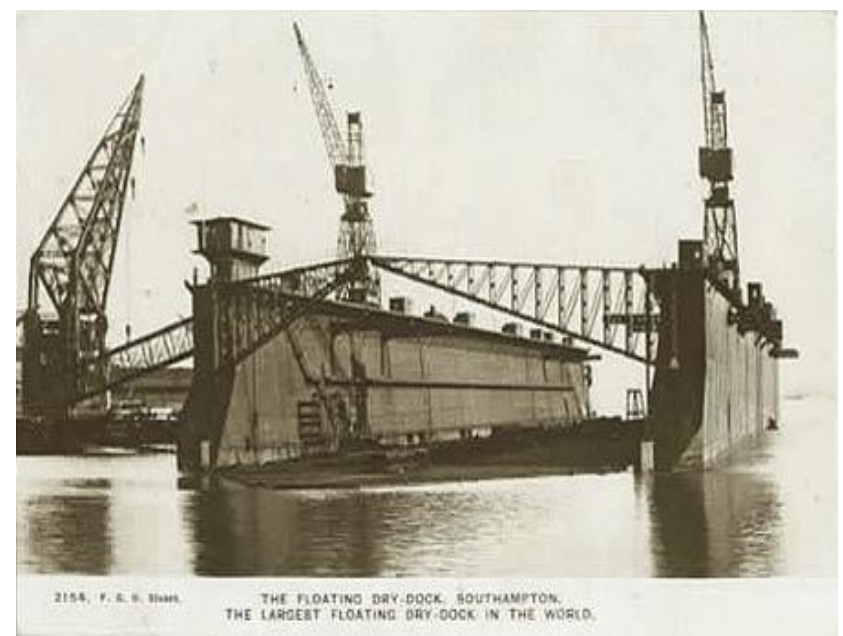

Gambar 1. Floating Dock

Pada prinsipnya menurut Cornick, Henry $F$. (1998) ada dua jenis konstruksi dari floating dock:

1. Jenis Box Dock yaitu sebuah konstruksi pontoon yang tidak terpisah-pisah menjadi beberapa pontoon sampai kedua sisi dinding floating dock.

2. Jenis Self Dock yaitu konstruksi pontoon yang dipisah-pisahkan menjadi beberapa bagian pontoon, sehingga salah satu pontoon bisa diangkat apabila membutuhkan perawatan / perbaikan.

Kelebihan floating dock adalah:

1. Lebih fleksibel karena dalam pengoperasiannya dapat menerima kapal trim maksimum $3^{\circ}$.

2. Floating dock dapat dipindah-pindahkan sesuai kebutuhan.

3. Waktu pembuatan konstruksi lebih cepat dibandingkan dengan graving dock.

4. Tidak tergantung pada kondisi struktur tanah.

Kelemahan floating dock adalah:

1. Banyaknya persyaratan yang bersifat membatasi operasi suatu dock apung (perairan di mana dock apung berada harus cukup dalam, tidak ada arus berlebihan, tidak ada angin berlebihan, tidak ada gelombang yang berlebihan).

2. Membutuhkan pengetahuan khusus dalam perawatan rutin.

\section{Satuan Perkapalan dan Istilah Penting pada Bangunan Kapal.}

a. Karene

Bagian-bagian dari kapal merupakan satuan-satuan yang mempunyai fungsi sendiri-sendiri seperti yang terdapat dalam paket instruksi. Karene adalah bentuk badan kapal yang ada di bawah permukaan air. Isi Karene adalah volume badan kapal yang ada di bawah permukaan air (tidak termasuk kulit dan lain-lainnya). Isi Karene dinyatakan dalam $\mathrm{m}^{3}$ oleh karena itu isi Karene adalah:

$$
\mathbf{V}=\mathbf{L} \cdot \mathbf{B} \cdot \mathbf{T} \cdot \mathbf{C b}
$$

Di mana:

$$
\begin{aligned}
\mathrm{V} & =\text { Isi Karene }\left(\mathrm{m}^{3}\right) \\
\mathrm{L} & =\text { Panjang Karene }(\mathrm{m}) \\
\mathrm{B} & =\text { Lebar Karene }(\mathrm{m}) \\
\mathrm{T} & =\text { Sarat kapal }(\mathrm{m}) \\
\mathrm{Cb} & =\text { Koefisien blok }
\end{aligned}
$$

b. Displacement

Adalah berat dari Karene dalam satuan ton. Kalau misalnya isi Karene adalah $\mathrm{V}$ dan berat jenis air dinyatakan dengan $\gamma$ maka:

$$
\mathrm{D}=\mathrm{V} \cdot \gamma
$$

Berat Pemindahan air $(\mathrm{W})$

Adalah air yang dipindahkan oleh badan kapal secara keseluruhan. Kalau berat jenis air dinyatakan dengan $\gamma$ maka $\mathrm{W}=\mathrm{V} \cdot \gamma$. Untuk kapal berat jenis air diambil $\gamma=1,025$ ton $/ \mathrm{m}^{3}$, sehingga selengkapnya:

$$
\begin{aligned}
& \mathrm{W}=\mathrm{V} \cdot \gamma \\
& \mathrm{W}=\mathrm{V} \cdot \mathrm{C} \cdot \gamma \\
& \mathrm{W}=\mathrm{L} \cdot \mathrm{B} \cdot \mathrm{T} \cdot \mathrm{Cb} \cdot \gamma \cdot \mathrm{C}
\end{aligned}
$$

Kapal yang terapung sesuai Hukum Archimedes, mengatakan bahwa setiap benda yang dimasukkan ke dalam air, benda tersebut mendapat gaya tekan ke atas sebesar berat zat cair yang dipindahkan dalam keadaan setimbang.

$$
\mathrm{P}=\mathrm{W}
$$

Dalam hal ini berat kapal sama dengan berat kapal kosong ditambah dengan bobot mati (dead weight) atau 
secara mudah dapat dituliskan bahwa :

$\mathrm{W}=\mathrm{DWT}+$ Berat kosong

Titik tekan dari gaya ke atas yang merupakan titik berat dari volume badan kapal yang terletak di bawah permukaan air disebut "Longitudinal Centre of Bouyancy" (titik tekan gaya ke atas memanjang) untuk arah memanjang dan "Vertical Centre of Bouyancy" (titik tekan gaya ke atas melintang) untuk arah tegak. Titik berat dari kapal sendiri untuk arah memanjang disebut "Longitudinal Centre of Gravity"dan untuk arah vertikal disebut "Vertical Centre of Gravity". Selanjutnya harus diingat pula bahwa gaya berat dari kapal bekerja dalam arah vertikal ke bawah, sedangkan displacement merupakan gaya tekan yang bekerja dalam arah vertikal ke atas rotasi yang sering digunakan:

$\Delta=\mathrm{L} . \mathrm{B} \cdot \mathrm{T} \cdot \mathrm{Cb} \cdot \gamma \cdot \mathrm{C}$

$\mathrm{V}=\mathrm{L} \cdot \mathrm{B} \cdot \mathrm{T} \cdot \mathrm{Cb} \cdot \mathrm{C}$

Di mana:

$\Delta=$ Displacement

$\mathrm{V}=$ Volume of displacement

c. Stabilitas benda terapung / kapal

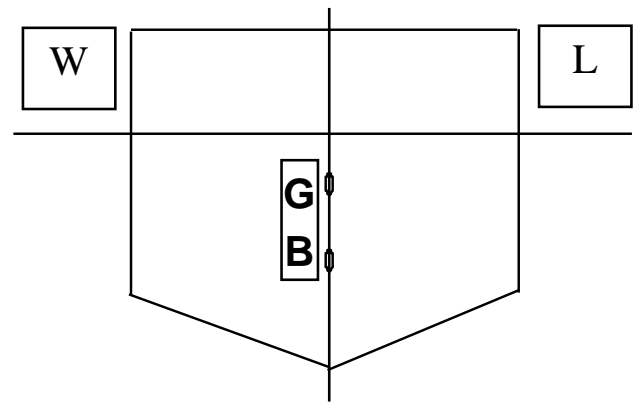

Gambar 2. Letak G dan B

1) Center of Gravity (G)

Center of gravity dari sebuah kapal / benda terapung lainnya adalah suatu titik di mana jumlah keseluruhan berat kapal itu dengan segala muatan yang ada di atasnya seolah-olah dipusatkan di titik $\mathrm{G}$ tersebut.

2) Center of Bouyancy (B)

Kapal yang terapung di atas air yang tenang, berat kapal dengan seluruh muatan yang ada di kapal itu adalah sama dengan air yang dipindahkan. Tekanan arah ke atas dari air sekelilingnya adalah sama dengan air yang dipindahkannya. Berat air yang dipisahkan ini memiliki arah ka bawah melalui Center of Gravity dari kapal dan inilah yang dinamakan Center of Bouyancy.

3) Depth / Kedalaman Dock $\left(D_{D}\right)$

Lloyd's Registerof Shipping (LR) menyatakan kedalaman dock (dalam meter/kaki) adalah jarak vertikal dari titik paling rendah dari bottom framing sampai tiang dinding bagian luar pada geladak paling atas.

$\mathrm{D}_{\mathrm{D}}=$ Lambung timbul sarat $\max +$ Tinggi ponton pada centreline.

4) Safety Deck

LR menyatakan safety deck adalah geladak kedap air (watertight deck) yang dibangun sedikit di bawah top deck di mana seluruh kompartement di bawah safety deck digenangi air kondisi tanpa beban di atas keel block. Hal ini disebabkan adanya free board antara top deck dan water line. Umumnya free board tidak boleh kurang dari 1 meter. Freeboard geladak pontoon pada centreline tidak boleh kurang dari 0,3 m. Freeboard geladak pontoon pada bagian dalam dinding samping tidak boleh kurang dari 0,075 $\mathrm{m}$ dan freeboard pada centreline tidak boleh kurang dari $0,3 \mathrm{~m}$.

5) Rest Water

LR menyatakan restwater adalah air ballast dalam tangki ballast yang tidak dapat dihisap oleh pompa ballast. Untuk rest water (sisa air yang tidak bisa dihisap) tingginya direncanakan sesuai dengan pipa hisap terhadap dasar pontoon $=10 \mathrm{~cm}=0,1$ meter.

6) Compensating Ballast Water

LR menyatakan compensating ballast water adalah air ballast yang digunakan untuk mengendalikan defleksi pada dock terhadap beban bending longitudinal.

Floating dock pada keadaan muatan penuh sedang malaksanakan docking kapal, diperlukan compensating ballast water sebesar $=10 \%$ sampai $15 \%$ dari lifting capacity.

7) Depth of Pontoon / Kedalaman Pontoon (DP)

LR menyatakan kedalaman pontoon adalah jarak vertikal antara bottom pontoon dan galadak pontoon. 


\section{Alat Tambat Floating Dock}

Agar floating dock tidak dapat bergeser akibat adanya gerakan air maupun ombak yang diakibatkan pergerakan kapal di air, maka diperlukan alat tambat tempat ditambatkannya floating dock. Pada umumnya mekanisme penambatan floating dock ada dua macam yaitu dengan jangkar dan dengan cara ditambatkan pada dolphin yang terpasang di darat atau dermaga.

\section{Daya Pompa}

Khetagurov, M. (1994) menyatakan daya yang diperlukan untuk menggerakkan pompa dihitung dengan rumus:

$$
\mathrm{Nu}=\frac{\mathrm{Q} \cdot \gamma \cdot \gamma}{60.60 \cdot 75 \cdot \eta}
$$

Di mana;

$\mathrm{Q}=$ Kapasitas pompa $\left(\mathrm{m}^{3} / \mathrm{jam}\right)$

$\gamma=$ Berat jenis air laut $\left(\right.$ ton $\left./ \mathrm{m}^{3}\right)=1,025$ ton $/ \mathrm{m}^{3}$

$=$ Berat jenis air tawar $=1,0$ ton $/ \mathrm{m}^{3}$

$\eta=$ Effisiensi pompa 0,5 sampai 0,9 ; diambil 0,7

$$
\mathrm{H}=\mathrm{Z}+\frac{\mathrm{P}}{\gamma}+\frac{\mathrm{V}^{2}}{2 \cdot \mathrm{g}}
$$

Di mana:

$$
\begin{aligned}
\mathrm{H} & =\text { head pompa }(\mathrm{m}) \\
\mathrm{Z} & =\operatorname{tinggi} \text { kenaikan }(\mathrm{m}) \\
\mathrm{P} & =\text { tekanan cairan }(\mathrm{kg} / \mathrm{m} 2) \\
\mathrm{V} & =\operatorname{kecepatan} \text { aliran }(\mathrm{m} / \mathrm{dt}) \\
\mathrm{g} & =\text { percepatan gravitasi }\left(\mathrm{m} / \mathrm{dt}^{2}\right)=9,81 \\
& \mathrm{~m} / \mathrm{dt}^{2}
\end{aligned}
$$

\section{METODE PENELITIAN}

\section{Alur Metode Penelitian}

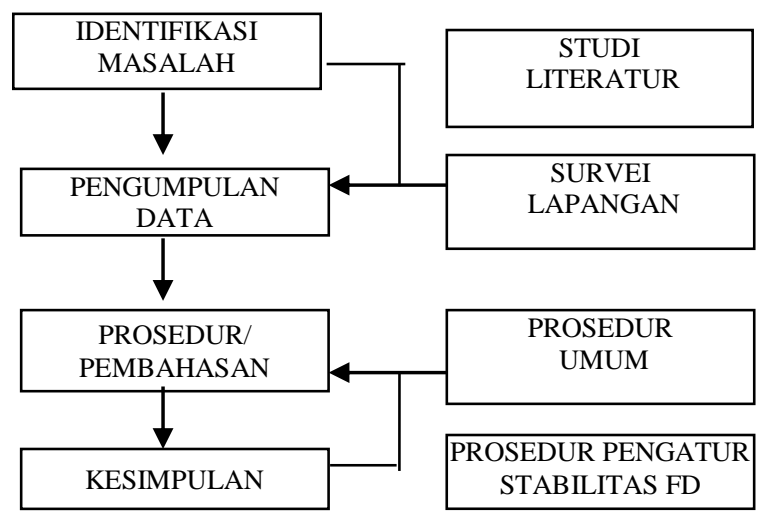

Gambar 3. Bagan Alur Metode Penelitian
Tabel 1. Uraian Metode Penelitian

\begin{tabular}{|c|l|l|}
\hline No & \multicolumn{1}{|c|}{ Kegiatan } & \multicolumn{1}{c|}{ Hasil } \\
\hline 1 & $\begin{array}{l}\text { Identifikasi } \\
\text { masalah }\end{array}$ & $\begin{array}{l}\text { Masalah kelebihan dan } \\
\text { kekurangan floating dock }\end{array}$ \\
\hline 2 & $\begin{array}{l}\text { Pengumpulan } \\
\text { data }\end{array}$ & $\begin{array}{l}\text { Data ukuran dan kapasitas dock, } \\
\text { data ukuran kapal }\end{array}$ \\
\hline 3 & $\begin{array}{l}\text { Penelusuran } \\
\text { prosedur }\end{array}$ & $\begin{array}{l}\text { Prosedur umum dan pengatur } \\
\text { stabilitas dock }\end{array}$ \\
\hline 4 & $\begin{array}{l}\text { Analisis dan } \\
\text { pembahasan }\end{array}$ & $\begin{array}{l}\text { Pelaksanaan prosedur umum } \\
\text { dan prosedur pengatur stabilitas } \\
\text { dock, proses pemompaan, } \\
\text { kapasitas ponton, alat kontrol }\end{array}$ \\
\hline 10 & Kesimpulan & $\begin{array}{l}\text { Floating dock 6000 TLC masih } \\
\text { mampu mengangkat Kapal } \\
\text { seberat 800 ton }\end{array}$ \\
\hline
\end{tabular}

\section{HASIL DAN PEMBAHASAN}

\section{Data-data Teknis}

\section{Data teknis floating dock}

Ukuran utama :

1) Panjang seluruh dok (Loa) $=130,80 \mathrm{~m}$

2) Panjang dok $($ Ldok $)=126,00 \mathrm{~m}$

3) Lebar ekstemal dok (Beks) $=21,41 \mathrm{~m}$

4) Lebar internal dok (Bint) $=19,41 \mathrm{~m}$

5) Tinggi Dok $(\mathrm{H})=11,72 \mathrm{~m}$

6) Tinggi ponton $(\mathrm{Hp})=3,22 \mathrm{~m}$

7) Sarat $(\mathrm{T})=4,50 \mathrm{~m}$

8) Tinggi puncak balok lunas $=1,20 \mathrm{~m}$

9) Jarak antara balok-balok $=1,23 \mathrm{~m}$

10)Daya angkat $\quad=6.000 \mathrm{TLC}$

Data-data lain:

1) Jumlah ponton $=7$ ponton

2) Jumlah pompa pengeringan kapasitas $1200 \mathrm{~m}^{3} / \mathrm{jam}$ adalah $=7$ unit

3) Motor bantu merk SKL,125 KVA = 1 unit

4) Motor in let/out let $22 \mathrm{kw}=4$ unit

5) In let $\&$ Out let $=7$ unit

6) Generator setting merk SKL kapasitas $330 \mathrm{KVA}$, adalah $=2$ unit

7) Motor onvoner $20 \mathrm{kw}$ merubah arus $\mathrm{AC}-$ DC : 1 Unit; In put $380 \mathrm{~V}$ (AC); Out put $110 \mathrm{~V}, 200 \mathrm{~V}, 200$ A (DC); Out put 220 $\mathrm{V}, 60 \mathrm{~A}$ (DC).

8) Motor blower kanan $(220 \mathrm{~V})=7$ unit

9) Motor Blower kiri (220V) =7 unit

10)Kompresor $60 \mathrm{KVA}=2$ unit

11)Capstan, $20 \mathrm{kw}$ kapasitas 5 ton $=4$ unit

12)Crane kapasitas 5 ton $=2$ unit

Data-data Kapal:

1) Panjang seluruh (Loa) $=90,75 \mathrm{~m}$

2) Panjang pada

permukaan air $(\mathrm{Lwl}) \quad=\quad 81,00 \mathrm{~m}$ 

3) Lebar (B)
$=\quad 15,60 \mathrm{~m}$
4) Sarat (T)
$=$
$3,75 \mathrm{~m}$
5) Tinggi sarat buritan $(\mathrm{Ta})=$
$4,20 \mathrm{~m}$
6) Tinggi sarat haluan $(\mathrm{Tv})=$
$3,30 \mathrm{~m}$
7) DWT
$=800,00$ ton
8) Berat kapal kosong (LWT)=
74,79 ton
9) Bruto register ton $(\mathrm{BRT})=$
218,09 Rt

\section{Proses Pemompaan}

Sistem pompa induk yang termasuk dalam general service system yang berfunsi menghisap air dari ruangan-ruangan di dalam ponton pada saat proses kerja dok menaikkan kapal. Sistim pemompaan ini harus dapat diatur sedemikian rupa sehingga pada proses pengedokkan tidak mengalami gangguan / hambatan yang dapat terjadi apabila sistim pemompaan tidak berjalan dengan baik. Pengaturan dari sistem pemompaan ini sangat penting karena dapat berpengaruh pada kestabilan dari proses kerja dok tersebut. Dengan kapasitas pompa tertentu yang sudah diperhitungkan dapat mengeluarkan air laut di dalam ponton kemudian disalurkan ke pipa-pipa pengeluaran untuk di buang ke laut hingga dok dapat terngkat kembali. Dari hasil data yang didapat bahwa, kapasitas pompa induk dari dok jayakerta III tiap-tiap unit memiliki kapasitas yang sama sebesar $1.200 \mathrm{~m}^{3} / \mathrm{jam}$.

Selanjutnya dari besarnya kapasitas pompa ini dapat diketahui kecepatan aliran air yang dikeluarkan melalui pipa-pipa pengeluaran. Dengan rumus yang didapat kecepatan aliran air di dalam pipa-pipa dapat dihitung sebagai berikut:

$$
V s=\frac{Q}{3600 x \frac{\pi}{4} x D^{2}}
$$

Di mana:

Vs $=$ Kecepatan aliran air $(\mathrm{m} / \mathrm{s})$

$\mathrm{Q}=$ Kapasitas pompa ( $\left.\mathrm{m}^{3} / \mathrm{jam}\right)$

$\mathrm{D}=$ Diamater pompa induk (mm).

Diameter pipa induk pada sistim pompa dok ini sebesar $76 \mathrm{~mm}$.

Dari rumus di atas dapat diketahui kacepatan aliran air di dalam pipa-pipa pengeluaran adalah:

$$
\begin{aligned}
V s & =\frac{1.200}{3600 \times \frac{3,14}{4} \times(0,76)^{2}} \\
& =73,520 \mathrm{~m} / \mathrm{s} .
\end{aligned}
$$

Maka dengan besarnya kecepatan aliran air dalam pipa dari hasil perhitungan di atas, mampu mengeluarkan air di dalam ponton yang berkapasitas $1.200 \mathrm{~m}^{3}$

\section{Sistem Peralatan Pengontrol.}

Mekanisme kerja Floating dock adalah secara mekanik. Pada pengoperasiannya saat membuka/ menutup katup-katup dengan cara menarik pedal handweel yang terdapat pada ruang pengontrol. Pada ruang ini terdapat meter penunjuk besarnya volume air di dalam ponton, meter petunjuk sarat air dok, dan meter untuk peralatan listrik, juga terdapat alat kestabilan dengan sistem grafitasi yang merupakan petunjuk dari kestabilan dok tersebut saat beroperasi. Pada pengoperasian dok saat menaikkan kapal, kemungkinan-kemungkinan kemiringan akan terjadi. untk menghindari kemiringan maka alt kestabilan ini akan menunjukan posisi pendulum tidak tepat pada garis lurusnya. Jika dok dalam menaikkan kapal terjadi miring ke kanan maka akan terlihat pada alat kestabilan dengan posisi ke arah kanan dari garis lurusnya.

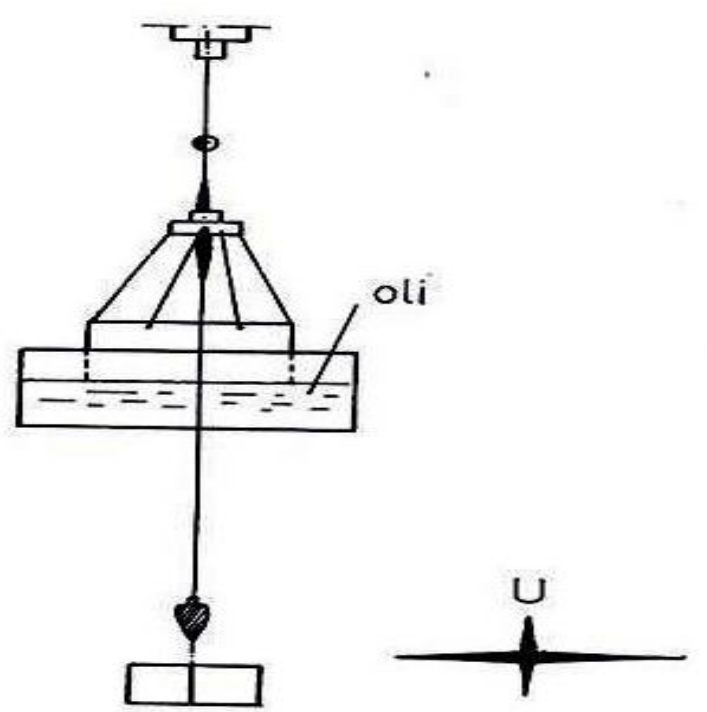

Gambar 4. Alat Kestabilan

Untuk menghindari katup kanan harus ditutup, kemudian katup pembagi ponton kiri di isi sampai sesuai sarat dok yang sudah di tentukan. Pada saat kapal mulai duduk diatas balok penumpu lunas (keel block) sering terjadi trim pada dok tersebut, pada kondisi ini merupakan kondisi yang kritis terhadap kestabilan dari floating dock. Dalam pengaturannya alat penunjuk kestabilan akan memperlihatkan posisi pendulum berada ke sebelah laut mak pengeluaran air pada ponton buritan harus di tutup, setelah rata terhadap 
sarat dok, baru dika kembali. Ketentuan tinggi sarat haluan dan buritan tidak lebih dari 3 meter. ("keselamatan pengedokan' Biro Dok Perkapalan Kodja Bahari UGJ-I)

\section{Kapasitas Ponton}

Pada floating dock terdiri dari 7 seksi ponton yang di bagi menjadi dua bagian yaitu bagian tangki sebelah kiri/portside dan bagian tangki sebelah kanan/startboard. Dari data-data yang didapat kedua bagian ini memiliki kapasitas tangki sebagai berikut:

Tabel 2. Kapasitas tangki bagian kanan

\begin{tabular}{|ccccc|}
\hline Ponton & $\begin{array}{c}\text { Panjang } \\
(\mathrm{m})\end{array}$ & $\begin{array}{c}\text { Lebar } \\
(\mathrm{m})\end{array}$ & $\begin{array}{c}\text { Sarat } \\
(\mathrm{m})\end{array}$ & $\begin{array}{c}\text { Kapasitas } \\
\left(\mathrm{m}^{3}\right)\end{array}$ \\
\hline \hline 0 & 20,50 & 7,80 & 3,22 & 514,878 \\
1 & 17,00 & 7,80 & 3,22 & 426,972 \\
2 & 18,80 & 7,80 & 3,22 & 472,181 \\
3 & 18,80 & 7,80 & 3,22 & 472,181 \\
4 & 18,80 & 7,80 & 3,22 & 472,181 \\
5 & 18,80 & 7,80 & 3,22 & 472,181 \\
6 & 17,00 & 7,80 & 3,22 & 426,972 \\
\hline
\end{tabular}

Tabel 3. Kapasitas tangki bagian kiri

\begin{tabular}{|ccccc|}
\hline Ponton & $\begin{array}{c}\text { Panjang } \\
(\mathrm{m})\end{array}$ & $\begin{array}{c}\text { Lebar } \\
(\mathrm{m})\end{array}$ & $\begin{array}{c}\text { Sarat } \\
(\mathrm{m})\end{array}$ & $\begin{array}{c}\text { Kapasitas } \\
\left(\mathrm{m}^{3}\right)\end{array}$ \\
\hline \hline 0 & 20,50 & 7,80 & 3,22 & 514,878 \\
1 & 17,00 & 7,80 & 3,22 & 426,972 \\
2 & 18,80 & 7,80 & 3,22 & 472,181 \\
3 & 18,80 & 7,80 & 3,22 & 472,181 \\
4 & 18,80 & 7,80 & 3,22 & 472,181 \\
5 & 18,80 & 7,80 & 3,22 & 472,181 \\
6 & 17,00 & 7,80 & 3,22 & 426,972 \\
\hline
\end{tabular}

Perhitungan Stabilitas melintang pada saat Dok menaikkan Kapal.

Diasumsikan bahwa pada stabilitas arah melintang saat dok menaikkan kapal mengalami kemiringan ke kanan sebesar 1,5 derajat pada posisi tegaknya. Untuk mengatasi kemiringan yang terjadi pada saat pengoprasiannya dengan cara menutup katup sebelah kanan selanjutnya katup pembagi ponton kiri di isi air sampai dok pada posisi tegak kembali dapat dihitung sbb :

1) Kapasitas daya angkat Dok $=6.000$ ton.

2) Sarat Dok $\quad=4,5 \mathrm{~m}$

3) Kemiringan arah melintang $=1,5$ derajat

4) Tinggi metasentra KM, sarat $4,5 \mathrm{~m}$ sebesar $10,40 \mathrm{~m}$.

Untuk menyelesaikan pemasalahan di atas, terlebih dahulu harus diketahui besarnya titik berat KG dari tiap-tiap beban yang ada di dalam ponton. Maka kondisi dalam pemasukkan air ke dalam tiap-tiap ponton sebelah kiri dan kanan adalah sebagai berikut:
Beban kanan (ton) $\quad \mathrm{KG}(\mathrm{m})$

$\begin{array}{lll}\text { Ponton } 1 & 800 & 1,50\end{array}$

Ponton $2 \quad 600 \quad 1,05$

Ponton $3 \quad 400 \quad 0,75$

Ponton $4 \quad 400 \quad 0,75$

Beban kiri yang harus di isi air:

\begin{tabular}{lcl}
\hline Beban kiri & (ton) & KG $(\mathrm{m})$ \\
Ponton 7 & 600 & 1,50 \\
Ponton 6 & 600 & 1,05 \\
Ponton 5 & 400 & 0,75
\end{tabular}

Dari hasil data-data di atas dapat ditentukan posisi dari titik gravitasi yang di dapat dari perhitungan momen stabilitas statis pada sudut sebesar $1,5^{\circ}$ yaitu:

Tabel 4. Parameter Stabilitas

\begin{tabular}{|c|c|c|}
\hline Displasemen (ton) & KG (m) & $\begin{array}{c}\text { Momen } \\
\text { (ton,m) }\end{array}$ \\
\hline $6.000,00$ & 4,42 & $26.520,00$ \\
800,00 & 1,50 & $1.200,00$ \\
600,00 & 1,05 & 630,00 \\
400,00 & 0,75 & 300,00 \\
400,00 & 0,75 & 300,00 \\
$8.200,00$ & & $28.950,00$ \\
Beban kiri yang di isi & & \\
800,00 & 1,50 & $1.200,00$ \\
600,00 & 1,05 & 630,00 \\
400,00 & 0,75 & 300,00 \\
\hline $6.400,00$ & \multicolumn{2}{|c}{} \\
\cline { 2 - 3 }
\end{tabular}

$\mathrm{KG}($ titik berat $)$ akhir $=\frac{26.820,00}{6.400,00}=4,20 \mathrm{~m}$

GM : Tinggi metasentra baru

KM : Tinggi metasentra pada Sarat 4,5m

KG : Titik berat akhir

Jadi $\mathrm{GM}=\mathrm{KM}-\mathrm{KG}$

$$
\begin{aligned}
& =10,40-4,20 \\
& =6,20 \mathrm{~m}
\end{aligned}
$$

Momen stabilitas statis pada 1,5 derajat

$=\Delta \mathrm{x} \mathrm{GM} \sin \varnothing$

$=6.400 \times 6,20 \sin 1,5^{\circ}$

$=1.038,70$ ton.m

Bila kedudukan dok yang tegak terhadap GZ tentunya harga GZ $=0$, dan GM cenderung kembali pada posisi semula, maka nilai GZ di dapat:

$$
\begin{aligned}
\mathrm{GZ} & =\mathrm{GM} \sin \varnothing \\
& =6,20 \sin 1,5^{\circ} \\
& =0,16 \mathrm{~m}
\end{aligned}
$$

Dari perhitungan dapat dilihat bahwa lengan jarak GZ sebesar 0,156, maka posisi dok kembali tegak. 


\section{Perhitungan Stabilitas Memanjang pada saat Dok menaikkan kapal.}

Air laut yang masuk kedalam ponton melalui katup pemasukkan akan terus dialirkan pada tiap-tiap sel-sel ponton sampai dok turun perlahan-lahan hingga batas sarat yang sudah ditentukan. Besarnya volume pengisian tiap-tiap ponton harus sama rata agar posisi dok tetap even keel. Tetapi, adanya pemindahan atau penambahan volume (beban) yang tidak merata pada buritan dok atau haluan dok akan menyebabkan letak dari titik berat $\mathrm{G}$ dari dok dan titik tekan ke atas B berpindah/bergeser secara memanjang terhadap garis tegak. Ini berarti bahwa keseimbangan dok tadi mengalami gangguan sehingga terjadi trim. Gangguan keseimbangan tersebut akan terus berlangsung sampai garis yang melalui $\mathrm{B}$ dan $\mathrm{G}$ merupakan garis yang tegak kembali. Untuk mengatasi keadaan seperti ini, apabila terjadi trim buritan dalam pengoperasian dok saat menaikkan kapal dengan cara menutup katup pembagi pada ponton 1 (buritan) sampai keadaan sarat mulai rata kembali. Ini juga dapat di lihat pada alat pengontrol kestabilan dengan arah posisi pendulum bergeser ke laut. Dalam perhitungan stabilitas memanjang dapat dibuktikan bahwa besarnya trim yang terjadi dapat diperkecil / dirubah berdasarkan peraturan atau ketentuan pada keselamatan pengedokan, yaitu besarnya trim atau perbedaan tinggi dari sarat haluan dan sarat buritan tidak lebih dari 3 meter. Untuk menghitung perbedaan tinggi saat haluan dan sarat buritan sesuai ketentuan dengan mencari besarnya volume dari ballast yang akan diisi pada ponton 6 (haluan). Dalam perhitungan ini diasumsikan kapal yang akan naik dok belum berada tepat di atas dok untuk mengatasi keadaan seperti ini, apabila terjadi trim buritan dalam pengoperasian dok saat menaikkan kapal dengan cara menutup katup pembagi pada ponton 1 (buritan) sampai keadaan sarat mulai rata kembali. Ini juga dapat dilihat pada alat pengontrol kestabilan dengan arah posisi pendulum bergeser ke laut.

Diketahui:

1) Kapasitas daya angkat dok 6.000 Tlc.

2) Tinggi metasentra memanjang ML $75 \mathrm{~m}$

3) Letak titik berat dari luasan garis airnya $(\mathrm{Z})$ sebesar 62,60 m, di depan Gtb dan 63,40 m di belakng Gtb, sehingga tinggi sarat haluan (Th) menjadi 3,30 $\mathrm{m}$ dan Tb sebesar 4,20 $\mathrm{m}$. Untuk dapat memperkecil tb sebesar $88 \mathrm{~cm}$ sehingga osisi kapal tetap even keel maka, dengan jalan mengisi tanki-tanki ponton haluan dan enutup katup pembagi ponton 1(buritan) dok tersebut. Jika diketahui jarak antara titik barat ponton buritan dengan ponton haluan sepanjang $100 \mathrm{~m}$.

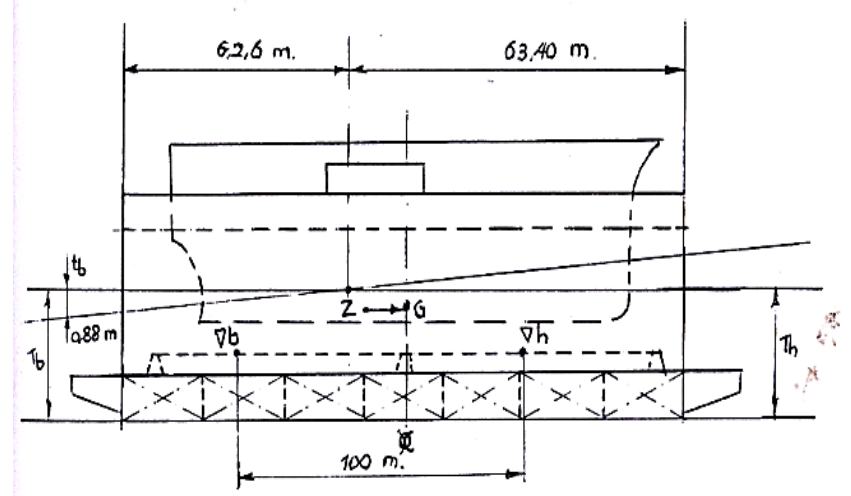

Gambar 5. Dok memanjang saat menaikkan kapal

Maka besarnya air laut yang diisi pada ponton haluan berdasarkan rumus pergerakan memanjang ("Stabilitas memanjang", Teori Bangunan Kapal Oleh Soekarsono N.A.) yaitu:

$\nabla \mathrm{h}=\frac{\text { tb. } \Delta \mathrm{b} . \Delta}{\text { Lb.l }}$

Di mana:

$\nabla \mathrm{h}=$ Berat air yang harus ditambahkan pada bagian ponton haluan (ton)

$\mathrm{Tb}=$ Jarak perubahan trim buritan $(\mathrm{m})$

$\Delta=$ Displasemen dok apung (ton)

ML = Tinggi metrasentra memanjang $(\mathrm{m})$

1 = Jarak antara titik berat ponton haluan dan ponton buritan (m)

Sehingga kapasitas air yang di isi pada ponton haluan adalah:

$$
\begin{aligned}
\nabla h & =\frac{0,88 \times 6.000 \times 75}{62,60 \times 100} \\
& =63,25 \mathrm{ton}
\end{aligned}
$$

Kemudian, besarnya tinggi sarat haluan dan tinggi sarat buritan yang terkhir dari dok tersebut sebesar:

$$
\begin{aligned}
& \text { th }=\operatorname{Lhx} \frac{\nabla h . l}{\Delta . M L G} \\
& \begin{aligned}
\text { th }= & 63,40 \times \frac{63,25 \times 100}{6000 \times 75} \\
& =0,90 \mathrm{~m}
\end{aligned}
\end{aligned}
$$

Karena ponton maka besar th $=$ tb maka:

$\mathrm{Th}^{\prime}=\mathrm{Th}+\mathrm{th}=3,30+0,90=4,20 \mathrm{~m}$

$\mathrm{Tb}^{\prime}=\mathrm{Tb}-\mathrm{tb}=4,20-0,90=3,30 \mathrm{~m}$ 


\section{KESIMPULAN}

Dari tinjauan terhadap prosedur pengatur kestabilan Floating dock secara keseluruhan dapat disimpulkan sebagai berikut:

1. Berat atau displasemen kapal yang akan naik dok besarnya masih dibawah kapasitas daya angkat dari dok tersebut. Kapal memiliki berat 800 ton, sehingga masih dapat dinaikkan pada Dok dengan kapasitas daya angkat sebesar $6.000 \mathrm{Tlc}$, dengan demikian bisa dikatakan masih memenuhi prosedur yang ada / aman.

2. Pemilik kapal sudah mempersiapkan datadata kapal berupa, gambar rencana garis, gambar penampang tengah kapal, gambar kontruksi profil, gambar rencana dok dari kapal (dock plan).

3. Sebelum kapal naik dok sudah diperiksa dan dipersiapkan dahulu tentang kondisi kapal tersebut yaitu panjang kapal antara garis tegak, lebar kapal tinggi kapal, sarat kapal pada ujung haluan dan ujung buritan yang dimaksud kapal harus sesuai dengan kondisi dok apung tersebut dan kapal diusahakan tanpa ada kemiringan arah melintang kemudian perbedaan sarat haluan dengan sarat buritan kapal tidak terlalu besar, Pada kapal yang memiliki ukuran kapal sebagai berikut:

a. Panjang seluruh (Loa) $=90,75 \mathrm{~m}$

b. Panjang di permukaan air $(\mathrm{Lwl})=81,00$ $\mathrm{m}$

b) Lebar (B) $\quad=15,60 \mathrm{~m}$

c) Sarat (T) $\quad=3,75 \mathrm{~m}$

d) Tinggi sarat buritan $(\mathrm{Ta})=4,20 \mathrm{~m}$

e) Tinggi sarat haluan $(\mathrm{Tv})=3,30 \mathrm{~m}$

f) DWT = 800 ton

Dari data-data kapal di atas dapat dilihat bahwa dengan kondisi dok yang memiliki ukuran dok:

1) Panjang seluruh (Loa) $=130,80 \mathrm{~m}$

2) Panjang dok (Ldok) $=126,00 \mathrm{~m}$

3) Lebar internal dok (Bint) $=19,41 \mathrm{~m}$

4) Sarat maksimum $(\mathrm{T}) \quad=4,50 \mathrm{~m}$

5) Kapasitas daya angkat $=6000$ ton

Maka pada proses pengedokkan kapal dapat dilaksanakan dengan memperhatikan saat dok menaikkan kapal. Pada kondisi ini, dok dapat menjaga kestabilannya dengan mengatur besarnya volume air yang masuk atau dikeluarkan dari dalam ponton oleh pompapompa induk dengan melihat alat pengontrol kestabilan sampai kapal tepat duduk di atas balok-balok penumpu lunas dok.

\section{REFERENSI}

Amirikian, Arsham, 1997. "Analysis and Design of Floating Dry docks", The Society of Naval Architects and Marine Engineers, New York.

Anugraha, Alex, 1987. "Perencanaan Dok Apung 5000 TLC Jenis Ponton", Tugas Akhir, Jurusan Teknik Perkapalan, Fakultas Teknologi Kelautan ITS, Surabaya.

BKI, 2006."Rules for The Classification and Construction of Sea Going Steel Ships, VolumeII, Rules for Hull Construction, Jakarta.

BKI, 2006."Rules for The Classification and Construction of Sea Going Steel Ships, Volume III, Rules for Machinery Instalation”, Jakarta.

Cornick, Henry F., 1998. "Dock and Harbour Engineering", Volume 1 The Design of Docks, Second Edition, Charles Griffin and Company Limited, London.

Harrington, Roy L., 1992. "Marine Engineering", The Society of Naval Architecs and Marine Engineers, 601 Pavonia Aveneu, Jersey City.

Khetagurov, M., 1954. "Marine Auxiliary Machinery and Systems", Peace Publishers, Moscow.

Lloyd's Register of Shipping, 1973. "Floating Docks, Rules and Regulation for the Construction and Classification of Floating Docks", Volume II, 71 Fenchurch Street, London. 